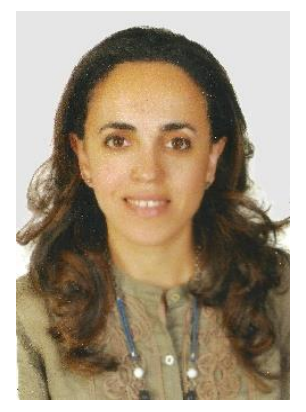

\title{
Sustainability and energy self-sufficiency; overcoming the barriers
}

\author{
Ass. Prof. Rania Abdel Galil
}

Engendering more positive attitudes to renewable energy is by no means a simple feat. Renewable energy technologies are viewed as radical innovations which necessitate substantial changes in production and consumption patterns, hence often met with resistance from both institutions and individuals. Yet action is needed; global energy consumption is expected to rise by $41 \%$ and global carbon dioxide emissions by $29 \%$, with most of the demand and rise coming from emerging economies (BP energy outlook 2035). Further, countries need to meet objectives of reduction of GHG under the United Nations Framework Convention on Climate Change. Renewable energy share in the global energy mix needs to significantly increase in order to reach supply sufficiency, energy security, energy equity and environmental sustainability.

Meeting demands of energy is critical for the economic and social development of any country; energy must be secure, accessible and affordable at all levels of society, and any negative impact of energy production and energy use on the environment must be minimized. Middle East energy consumption is expected to grow by $69 \%$ whilst production to grow by $32 \%$, with $97 \%$ of demand still met by fossil fuels by the end of the 2035. Energy investment of $\$ 316$ billion will be required in the Middle East and North Africa (MENA) between 2015 and 2019 to meet its growing demand for power (Apicorp, 2014). Diversifying energy sources is indeed of interest in the MENA region, spurred by growing demand for power and desalinated water, fluctuating fuel price, GHG emission reduction targets, depleting fossil fuel reserves and advances in renewable energy technology. However, there are many barriers that hinder the adoption of renewable energy technologies worldwide, but more so in the MENA region. These barriers are political, economic, social and technological. With a focus on Europe and MENA, it can be said that these barriers have much in common albeit framing the struggle on the micro level in Europe and on the macro level in MENA.

On a political level, renewable energy policies in Europe are criticized as being uncoordinated, unstrategised and based on multiple interests, generally favouring macro level and inadequate to stimulate widespread adoption at the micro level. Similarly, in the MENA region, there is a lack of coordination between sustainable energy policies with other policy fields, namely economic, financial, environmental and social policy, with a lack of expertise in renewable energy policies and supportive policies for private investment. On an economic level, in Europe, sourcing and accessing finance is a major barrier for communities, with a lack appropriate organizational structures, the volatility of grant regimes and uncertain infrastructural costs perhaps associated with the near monopolistic position of some grid companies. Whereas in the MENA region, there are no incentives for economical use of energy, there is a lack of funding in public utilities in most countries, the investment climate is less attractive and a monopoly position of most electricity producers exists. 
Technically, on a national level in Europe, a problem of the incompatibility of the new technologies with the current infrastructure (grid connection and capacity) are often identified as barriers, whilst on a community level, the lack of data on the efficiency of techniques, lack of technical skills and experience to implement renewable energy solutions act as barriers. In MENA, technologies involving the use of renewables have barely become established on the market and there is a significant lack of knowledge in the areas of technology transfer, marketing and the development of services within the energy sector. Finally, on a social level, the picture in the MENA region is bleaker. In Europe, governments and communities are well aware of the challenges laying ahead in terms of energy and some are well underway in achieving targets on the energy sustainability front (WEC, 2013). That is not to say that social barriers do not exist. They are manifested in the hindrance of knowledge transfer between social actors including misinformation, inadequate public consultation, and lack of inertia, access to relevant professional services, expertise and skills. Also, community concern over aesthetics, environmental issues and a perception of unequal distribution of benefits. However, in the MENA there is barely any awareness on the issue of energy security, equity and sustainability among individuals and the society, with lack of education and information on production and consumption, and no incentives for change. The rate of adoption, although not homogenous across the region, has been slow to date. Policy makers will not be persuaded to change, as a bottom-up approach is unlikely and the market will not develop accordingly, for lack of demand. Also, top-bottom approaches will be ineffective as the adoption of new systems are often met with resistance and the uptake will require change of entrenched practices and incentives for adoption.

Challenges to the wider adoption of renewable energy lie in two areas; provision and choice. The later can be overcome by awareness campaigns, incentive-based initiatives, and involving and empowering individuals and local communities in the development of renewable energy solutions. There is an urgent need to support initiatives in the MENA region to collaborate on environmental and energy related issues, build capacities to enable civil society engagement in the context of developing and implementing national energy plans and increase awareness on the needed shift towards a sustainable energy future. Meaningful global price for carbon is but one example to provide incentives for everyone to play their role in meeting the world's increasing energy needs whilst combating climate change and maintaining good air and water quality. To conclude, a quote by the United Nations Secretary-General Ban Ki-moon comes to mind: "energy is the golden thread that weaves together economic growth, social equity, and environmental sustainability". If sustainable development is to be realized, if there is to be a universal access to modern energy services and energy self-sufficiency, the share of renewable energy sources and the global rate of improvement in energy efficiency need to intensify, in addition to a strong shift of attitudes and policy towards cleaner choices of energy.

\footnotetext{
About Ass. Prof. Rania Abdel Galil

Associate Professor Rania Abdel Galil has graduated from Alexandria University, Faculty of Engineering. She was appointed in the Arab Academy for Science, Technology and Maritime Transport (AASTMT) till present. She received her PhD from Sheffield University, United Kingdom in 2007. Following her PhD, she accepted an appointment in the Department of Town and Regional Planning, Sheffield University, UK, where she taught for two years. During that time, she was a member in a winning bid for a research commissioned by the Parliamentary Commissioner for the Environment, New Zealand. She is now an associate professor in the Department of Architectural Engineering and Environmental Design, AASTMT. Besides teaching, she acted as RIBA coordinator over the last 5 years and currently liaises for international relations and training opportunities. Rania has presented in many international conferences, has been a member of the scientific and organizing committees and actively participated in numerous workshops and symposiums. She is the Associate-Editor of the Journal of Renewable Energy and Sustainable Development (Egypt) and an Editorial board member of the International Development Planning Review Journal (UK). She is a peer reviewer in several journals, supervised numerous $\mathrm{PhD}$ and MSc theses and has published over 20 research papers. Her research interests are in sustainability and the North/South divide.
} 